\title{
Overcoming Barriers to the Effective Management of Severe Asthma in Italy
}

\author{
Pierluigi Paggiaro' \\ Simona Barbaglia ${ }^{2}$ \\ Stefano Centanni ${ }^{3,4}$ \\ Davide Croce $\mathbb{D}^{5}$ \\ Enrico Desideri ${ }^{6}$ \\ Saffi Giustini ${ }^{7,8}$ \\ Claudio Micheletto 9 \\ Antonino Musarra ${ }^{10}$ \\ Nicola Scichilone (D) ${ }^{11}$ \\ Ugo Trama ${ }^{12}$ \\ Maria Teresa Zedda ${ }^{7,13}$ \\ Giorgio Walter Canonica ${ }^{14}$ \\ 'Department of Surgery, Medicine, \\ Molecular Biology, and Critical Care, \\ University of Pisa, Pisa, Italy; ${ }^{2}$ Associazione \\ Nazionale Pazienti "Respiriamo Insieme", \\ Padova, Italy; ${ }^{3}$ Department of Health \\ Sciences, Università degli Studi di Milano, \\ Milan, Italy; ${ }^{4}$ Respiratory Unit, ASST Santi \\ Paolo e Carlo, Milan, Italy; ${ }^{5}$ Center for \\ Health Economics, Social and Health Care \\ Management, LIUC-Università Cattaneo, \\ Castellanza, Italy; ${ }^{6}$ Fondazione Innovazione \\ e Sicurezza in Sanità, Rome, Italy; ${ }^{7}$ Italian \\ General Practitioners' Association "SIMG", \\ Florence, Italy; ${ }^{8}$ Local Health Unit of \\ Montale, Pistoia, Italy; ${ }^{9}$ Cardio-Thoracic \\ Department, Respiratory Unit, Integrated \\ University Hospital, Verona, Italy; ${ }^{10}$ Allergy \\ Unit, National Healthcare System, Reggio \\ Calabria, Italy; "'Biomedical Department of \\ Internal and Specialist Medicine, University \\ of Palermo, Palermo, Italy; ${ }^{2}$ Dirigente UOD \\ 06 Politica del Farmaco e Dispositivi, Naples, \\ Italy; ${ }^{13}$ General Practice, Cagliari, Italy; \\ ${ }^{14}$ Personalized Medicine Asthma \& Allergy \\ Clinic, Humanitas University and Research \\ Hospital-IRCCS, Milan, Italy
}

Correspondence: Pierluigi Paggiaro Department of Surgery, Medicine, Molecular Biology and Critical Care, University of Pisa, Via Paradisa No. 2, Pisa, 56/24, Italy

Tel +39050 995365

$\mathrm{Fax}+39050580124$

Email pierluigi.paggiaro@unipi.it
Introduction: People with severe asthma (SA) often have poor disease control and quality of life, and are at high risk of exacerbations, lung function decline and asthma-related death. The present expert opinion article aimed to identify unmet needs in the management of SA in Italy, and propose possible solutions to address these needs.

Methods: At five multidisciplinary events in Italy, attendees identified factors that interfered with the effective management of SA and suggested how these barriers could be overcome. A core group of 12 Italian experts (pulmonologists, general practitioners, allergists, payers and patients) identified the main issues and proposed possible solutions based on the results from the meetings and relevant articles from the literature.

Results and Conclusions: We reviewed the gap between real-world practice and guidelines, oral corticosteroid overuse, SA-related mortality, and barriers to effective SA treatment. Common themes were lack of awareness about SA among both patients and clinicians, and lack of networking/information exchange between those involved in the treatment of SA. Participants agreed on the need to implement patient education and create multidisciplinary groups of specialists to improve SA management through multidisciplinary educational initiatives, meetings with local experts, development of a flow chart for referral/connection with local experts and specialized centers. Clinical instruments that might help specialists improve SA management included referral networks, integrated care pathways, phenotyping and treatment algorithms, exacerbation tracking, and examination of electronic medical records for patients with uncontrolled asthma. The following actions need to be implemented in Italy: i) maximize the use of advanced therapies, eg, biologics; ii) increase/improve education for physicians and patients; iii) improve multidisciplinary communication and care coordination; iv) introduce regional and local protocols for SA diagnosis and treatment; and v) change the structure of healthcare services to reduce specialist waiting times and facilitate access to biologic therapies.

Keywords: biologic therapy, expert opinion, oral corticosteroids, severe asthma, unmet needs

\section{Introduction}

Asthma is a chronic respiratory disease characterized by airway inflammation and airflow obstruction. ${ }^{1}$ Asthma affects more than 300 million people worldwide, of whom between $3.5 \%$ and $10.0 \%$ are believed to have severe asthma. ${ }^{2-5}$ Several definitions of severe asthma have been proposed over the years. ${ }^{6}$ Currently, it is defined as asthma that requires high-dose anti-inflammatory therapy to achieve disease control, or asthma that remains uncontrolled despite such therapy. ${ }^{3,6}$ Severe asthma is a heterogeneous condition and its natural history is poorly understood. $^{1,3,7}$ A range of factors, including genetic predisposition, medical 
history, comorbidities, and smoking, appear to play a role in the development of severe asthma. ${ }^{3}$

According to the European Respiratory Society (ERS)/ American Thoracic Society (ATS) guidelines, ${ }^{3}$ severe asthma is defined as the condition that requires regular use of high doses of inhaled corticosteroids (ICS) in combination with a second controller and/or systemic corticosteroids to be controlled, or that remains uncontrolled despite such treatment. ${ }^{3,14}$ The 2020 Global Initiative for Asthma (GINA) recommendations define this condition as difficult-to-treat asthma, while severe asthma is a subset of difficult-to-treat disease that remains uncontrolled despite treatment with maximal optimized therapy or that worsens if such treatment is withdrawn. ${ }^{1}$ These definitions assume that the differential diagnosis of asthma has been established, that comorbidities have been optimally treated, and that environmental factors and poor adherence or inhaler technique have been excluded as reasons for lack of control. ${ }^{14}$ Therefore, the definition of severe asthma requires repeated observations of ongoing symptoms in patients whose treatment has been optimized.

Severe asthma imposes a substantial burden on the patient, the healthcare system and society at large. Patients with severe asthma are more likely to have poorly controlled symptoms, decreased lung function and exacerbations than patients with mild or moderate asthma. ${ }^{3}$ Furthermore, patients with severe asthma, especially those with comorbidities or high peripheral eosinophil levels, often use systemic corticosteroids at high doses and frequencies, and therefore are at increased risk of developing corticosteroid-related adverse events. ${ }^{8,9}$ Severe asthma also has a negative effect on the patients' emotional wellbeing, their relationships with friends and family, and on their career. ${ }^{10,11}$ Although severe asthma affects a minority of patients, it is responsible for most of the costs associated with this disease. ${ }^{12,13}$

The aim of the present expert opinion article was to identify unmet needs in the management of severe asthma in Italy, and to propose possible solutions for addressing these needs in the context of the Italian Health Service.

\section{Methods}

In 2018 and 2019, five macroregional events and one multidisciplinary group meeting were held, at which panels of Italian experts, including pulmonologists, general practitioners (GPs), allergists, National Health Service (NHS) payers and representatives of patients' associations, discussed the diagnosis and treatment of patients with severe asthma. The meetings were organized according to geographic location, with participants from: Lombardy and Trentino-Alto Adige; Piedmont, Liguria and Aosta Valley; Sicily, Calabria and Basilicata; Lazio, Tuscany and Sardinia; and Campania and Apulia. Attendees were local allergists, pulmonologists, and GPs known to be experienced in the management of severe asthma. Attendees were invited to participate independently of the sponsoring pharmaceutical company, based on the physicians' publication history, reputation and curriculum vitae. During the meetings, panels of experts (total $n=58$ ) and attendees (total $n=127$ ) were asked to identify the barriers that, in their opinion, interfered with the effective management of severe asthma and to suggest how these barriers could be overcome. At the end of the meetings, the attendees and panel of experts were asked to complete a written survey $(n=86)$, designed to identify the impact of various barriers on patients with severe asthma. This survey was performed by an external Italian agency (Sentrix Global Health Communications Srl) well experienced in observational surveys, working in agreement with the current European regulations about the privacy of the collected opinions. This company is maintaining a copy of all documents. According to Italian regulations, this type of consultative research activity (similar to demoscopic assessment) does not require Ethics committee approval. Attendees were fully informed about the nature of the survey and the anonymity of the survey results in their invitation to the meeting. Consent to participate was implicit in their attendance at the meeting. The authors of the present manuscript had access only to anonymous mean or median data.

In order to place the information gathered from the expert meetings in context, a review of relevant literature was conducted. Results from the macroregional events and relevant articles were discussed by the multidisciplinary group of 12 Italian experts, including pulmonologists, GPs, allergists, NHS payers and representatives of patients' associations. Based on this discussion and after reaching a general consensus, the main issues were identified and possible solutions were proposed.

No statistical analysis was necessary, considering the descriptive nature of the article.

\section{Results}

Based on the results of the literature review and the discussions at the macroregional events, the following issues were identified. 


\section{Gap Between Real-World Practice and Guideline Recommendations \\ Recommended Management of Severe Asthma}

According to the GINA guidelines, ${ }^{1}$ the recommended approach to the management of difficult-to-treat asthma includes several steps: i) evaluation of the patient's adherence to the recommended treatment and the correct use of inhalers, considering the possibility of switching to ICSformoterol as maintenance and reliever therapy; ii) verification that the diagnosis of asthma has been performed correctly considering the typical asthma symptoms and risk factors, as well as demonstration of a variable airway obstruction; iii) evaluation and appropriate management of any comorbidities potentially responsible for poor asthma control; iv) avoidance or minimization of the trigger factors (eg allergen exposure, environmental or occupational pollutants, and smoking); and v) optimization of treatment with currently available inhaled drugs (ie, ICS, long-acting $\beta 2$-agonist, long-acting muscarinic antagonist). If the patient remains uncontrolled at the end of this complex process of assessment (which may require several weeks or months to complete), then he or she should be considered to have severe uncontrolled asthma and should undergo the following steps: i) pheno-endotyping of asthma that takes into consideration clinical history, comorbidities and biomarkers; ii) in the case of a type 2 pattern of inflammation, treatment with biologic drugs should be considered. The biologic agents that are currently available for the treatment of severe asthma are monoclonal antibodies that target immunoglobulin E (omalizumab), interleukin (IL)-5 (mepolizumab), IL-5 receptor $\alpha$ (benralizumab), or the IL-4 receptor (dupilumab). ${ }^{15}$ While these agents provide a highly effective treatment option for many patients with severe asthma, ${ }^{16-19}$ their high cost means that they should be reserved for those most likely to benefit. Unfortunately, very few treatment options (and in particular, no biologic drugs) are currently available for patients with severe asthma who have non-type 2 inflammation, and these patients have a poor prognosis. In these patients, lowdose oral corticosteroids (OCS) can be considered as second-line add-on therapy, although special attention is needed to minimize adverse effects. ${ }^{1}$

After a treatment has been started, frequent assessment of its efficacy in terms of improving symptoms, reducing the exacerbation rate, and improving pulmonary function and quality of life should be performed in order to verify that the treatment is appropriate and to determine whether it should be continued. However, if the efficacy of the treatment regimen is inadequate, a switch to another alternative may be required.

\section{Management of Severe Asthma in Real-World Practice}

There is reason to believe that guideline recommendations are not followed in real-world clinical practice. ${ }^{20,21}$ In a study that included 107 Italian GPs and 995 patients with asthma, $28.8 \%$ of patients received treatment that adhered to the 2009 GINA guidelines. ${ }^{20}$ In this study, the use of guideline-compliant treatment was significantly associated with disease control. ${ }^{20}$

Studies consistently find that asthma is poorly controlled in a large proportion of patients. ${ }^{22,23}$ The Epidemiology and Natural History of Asthma: Outcomes and Treatment Regimens (TENOR I) study provided important insights into the epidemiology and outcomes of patients aged $>6$ years with severe or difficult-to-treat asthma. ${ }^{24}$ The TENOR I study included 807 patients with very poorly controlled asthma, as defined in the 2007 National Heart, Lung, and Blood Institute (NHLBI) guidelines; only a small proportion of these patients showed improvement over 24 months, with $62.2 \%$ of children (6-11 years old) and $75.0 \%$ of adolescents and adults ( $\geq 12$ years old) having consistently very poorly controlled asthma during follow up. ${ }^{24}$ Subsequently, the TENOR II study, which followed 341 patients from the TENOR 1 study for $>10$ years, showed that the majority of patients continued to have very poorly controlled asthma during this long-term follow-up period. ${ }^{25}$

Poor disease control in patients with asthma is associated with a number of adverse outcomes, such as increased risk of unscheduled office visits, OCS bursts, emergency room visits and hospitalizations, and worsening quality of life and general health status. ${ }^{26,27}$ Data from the Italian Severe Asthma Registry support these findings, and show that an increased rate of exacerbations, lung function decline, and corticosteroid-induced morbidity and mortality are associated with poor control of severe asthma in Italian patients. ${ }^{7,28}$

\section{Overuse of Oral Corticosteroids}

A major issue in the management of asthma, and particularly severe asthma, is the overuse of OCS treatment. ${ }^{14}$ The GINA guidelines have always listed low-dose OCS as an option for add-on therapy in patients with severe 
asthma, but from 2014, low-dose OCS was recommended as a second-line therapy in this setting, with biologic therapy being the preferred option. ${ }^{15}$ In addition, from 2019, the GINA guidelines noted that physicians should consider the adverse effects of low-dose OCS when prescribing them for severe asthma. ${ }^{16}$ The adverse events known to be associated with OCS include hypertension, osteoporosis and bone fracture, cataract and glaucoma, diabetes, respiratory infections, reduced growth velocity in children, and hypothalamic-pituitary-adrenal axis suppression. $^{13}$ A study of long-term medical records from 24,117 adult patients with asthma treated with systemic corticosteroids who were matched with an equal number of patients with no systemic corticosteroid exposure showed that systemic corticosteroids were associated with a significantly higher risk of osteoporosis and bone fracture, pneumonia, cardio- or cerebrovascular disease, cataracts, sleep apnea, renal impairment, depression or anxiety, type 2 diabetes, and bodyweight gain. ${ }^{17}$ The risk of these adverse events increased in a dose-dependent manner. ${ }^{17}$ Two systematic literature reviews reported similar findings, and also provided evidence that a higher dose and duration of systemic corticosteroid treatment are associated with increased healthcare costs. ${ }^{18,19}$

OCS are widely used in patients with severe asthma in Italy. For example, in a study of 437 consecutive patients with severe asthma from the Severe Asthma Network in Italy (SANI), 64.1\% were prescribed OCS. ${ }^{20}$ Another study conducted in a cohort of Italian patients with severe asthma, who were identified using the Health Search Database from GPs, found that $76.1 \%$ received OCS at the time of diagnosis. ${ }^{21}$ In Italy, the annual healthcare costs per patient due to OCS-related adverse events have been estimated at $€ 1957.50$ for severe asthma, compared with $€ 1350.96$ for mild or moderate asthma. ${ }^{13}$ Based on an estimated 199,980 patients with severe asthma in Italy, the total annual healthcare costs associated with OCS-related adverse events were calculated to be $€ 242.7$ million. $^{13,20}$ The adverse events and costs of OCS explain why, since 2019, the GINA guidelines have recommended that these agents should be used only as a second-line option for patients with severe asthma who do not respond to, or are unable to take, other options such as biologic agents. ${ }^{1,16}$

\section{Preventable Mortality}

Although deaths due to asthma declined in most countries by approximately 50\% between 2001-2005 and 2011-2015, it is estimated that in 2016 there were
420,000 asthma-related deaths worldwide. ${ }^{2}$ Many asthmarelated deaths are believed to be preventable and result from a lack of appropriate treatment. ${ }^{22-24}$ In the United Kingdom (UK), approximately $40 \%$ of asthma-related deaths are thought to have occurred in patients with severe asthma. $^{24}$ Furthermore, long-term OCS use in these patients is associated with an increased risk of mortality. ${ }^{25,26}$

\section{Barriers to Effective Management of Severe Asthma}

The GINA guidelines emphasize the importance of patients' goals and satisfaction in the effective management of asthma. ${ }^{1}$ Recently, a group of academics, patient advocates, and representatives from professional organizations developed a Charter for the Care of Patients with Severe Asthma, with the goal of improving the quality of care for this condition. $^{27}$ The charter includes six principles that are intended to outline what patients with severe asthma should expect from treatment and what should constitute a basic standard of care (Table 1). ${ }^{27}$ Nevertheless, a number of barriers prevent patients achieving optimal care. ${ }^{28-34}$

\section{Barriers to Severe Asthma Diagnosis and Management in Italy}

The barriers to effective diagnosis and management of severe asthma in Italy that were identified during the five multidisciplinary meetings are presented in Table 2 . These barriers were classified based on whether they impacted mostly GPs and specialists, patients and caregivers, or healthcare providers, and whether they related to diagnosis, management, or follow-up. Two common themes

Table I Charter to Improve Patient Care in Severe Asthma

\begin{tabular}{|l|l|}
\hline Principle & \\
\hline I & $\begin{array}{l}\text { I deserve a timely, straightforward referral when my } \\
\text { severe asthma cannot be managed in primary care. }\end{array}$ \\
\hline 2 & $\begin{array}{l}\text { I deserve a timely, formal diagnosis of my severe asthma } \\
\text { by an expert team. }\end{array}$ \\
\hline 3 & I deserve support to understand my type of severe asthma. \\
\hline 4 & $\begin{array}{l}\text { I deserve care that reduces the impact of severe asthma } \\
\text { on my daily life and improves my overall quality of care. }\end{array}$ \\
\hline 5 & I deserve not to be reliant on oral corticosteroids. \\
\hline 6 & $\begin{array}{l}\text { I deserve to access consistent quality care, regardless of } \\
\text { where I live or where I choose to access it. }\end{array}$ \\
\hline
\end{tabular}

Note: Data from Menzies-Gow et al. ${ }^{27}$ 
Table 2 Barriers to Effective Management of Severe Asthma in Italy According to Various Stakeholders

\begin{tabular}{|l|l|}
\hline \multicolumn{2}{|l|}{ Barriers to Correct and Timely Diagnosis } \\
\hline $\begin{array}{l}\text { According to GPs and } \\
\text { pulmonary specialists }\end{array}$ & $\begin{array}{l}\text { Failure to identify severe asthma } \\
\text { Failure/delayed referral to a specialist by } \\
\text { GPs } \\
\text { Poor communication between GPs, } \\
\text { specialists and first aid providers } \\
\text { Lack of awareness of severe asthma } \\
\text { among clinicians }\end{array}$ \\
\hline $\begin{array}{l}\text { According to patients } \\
\text { and/or caregivers }\end{array}$ & $\begin{array}{l}\text { Lack of patient awareness and self- } \\
\text { management } \\
\text { Poor treatment adherence }\end{array}$ \\
\hline According to health \\
system providers & $\begin{array}{l}\text { Poorly structured clinics } \\
\text { Long waiting lists } \\
\text { Lack of collaboration between various } \\
\text { specialists } \\
\text { Lack of awareness of severe asthma in } \\
\text { the wider society }\end{array}$ \\
\hline
\end{tabular}

\section{Barriers to Effective Therapeutic Management}

\begin{tabular}{|l|l|}
\hline $\begin{array}{l}\text { According to GPs and } \\
\text { pulmonary specialists }\end{array}$ & $\begin{array}{l}\text { Underuse and poor availability of } \\
\text { biomarkers to guide treatment decisions } \\
\text { Absence of an OCS-use monitoring } \\
\text { system } \\
\text { Underuse of phenotyping by specialists } \\
\text { Treatment of acute phases only } \\
\text { Failure to check adherence to therapy }\end{array}$ \\
\hline $\begin{array}{l}\text { According to patients } \\
\text { and/or caregivers }\end{array}$ & $\begin{array}{l}\text { Poor patient education and } \\
\text { empowerment } \\
\text { Fear of having to resort to using } \\
\text { systemic corticosteroids }\end{array}$ \\
\hline According to health & $\begin{array}{l}\text { Cost of biologic drugs } \\
\text { Lack of real-world epidemiological data } \\
\text { in Italy } \\
\text { Absence of a structured network and } \\
\text { lack of collaboration between GPs, } \\
\text { specialist prescribers of biologic agents, } \\
\text { and non-prescribing specialists } \\
\text { Lack of key performance indicators }\end{array}$ \\
\hline According to patients \\
and/or caregivers & $\begin{array}{l}\text { Lack of trust between patients and } \\
\text { clinicians } \\
\text { Poor treatment adherence }\end{array}$ \\
\hline pulmonary specialists & $\begin{array}{l}\text { Lack of follow-up planning } \\
\text { schedule and poor GP involvement } \\
\text { Underuse of biomarkers to guide } \\
\text { treatment decisions }\end{array}$ \\
\hline to Effective Fol Up
\end{tabular}

(Continued)
Table 2 (Continued).

\begin{tabular}{|l|l|}
\hline $\begin{array}{l}\text { According to health } \\
\text { system providers }\end{array}$ & $\begin{array}{l}\text { Absence of a structured network and } \\
\text { lack of collaboration between GPs, } \\
\text { specialist prescribers of biologic agents } \\
\text { and non-prescribing specialists } \\
\text { Logistic difficulties (distribution of } \\
\text { centers in the area) } \\
\text { Scarcity of economic and personnel } \\
\text { resources } \\
\text { Lack of key performance indicators }\end{array}$ \\
\hline
\end{tabular}

Abbreviations: GP, general practitioner; OCS, oral corticosteroids.

emerged from the discussion: i) lack of awareness about severe asthma among both patients and clinicians, and ii) lack of networking and information exchange between those involved in the treatment of severe asthma. The findings of the short survey that was conducted to explore the impact of specific barriers are presented in Table 3.

Table 3 The Impact of Various Barriers to Effective Management of Severe Asthma (Survey Results)

\begin{tabular}{|l|l|}
\hline Barriers & Major Consequences \\
\hline $\begin{array}{l}\text { Delay in referral to a center with } \\
\text { special expertise in the field of } \\
\text { severe asthma }\end{array}$ & $\begin{array}{l}\text { Risk of serious exacerbations } \\
\text { Decreased quality of life } \\
\text { Late diagnosis }\end{array}$ \\
\hline Incorrect diagnosis & $\begin{array}{l}\text { Risk of serious exacerbations } \\
\text { Decreased quality of life } \\
\text { Inappropriate treatment }\end{array}$ \\
\hline Late diagnosis & $\begin{array}{l}\text { Risk of serious exacerbations } \\
\text { Decreased quality of life } \\
\text { Disease progression/airway } \\
\text { remodeling } \\
\text { Increased mortality risk }\end{array}$ \\
\hline $\begin{array}{l}\text { Delay/failure to attend follow-up } \\
\text { after receiving first aid } \\
\text { treatment }\end{array}$ & $\begin{array}{l}\text { Risk of serious exacerbations } \\
\text { Inappropriate use of OCS } \\
\text { Absence of monitoring of the } \\
\text { number and severity of } \\
\text { exacerbations }\end{array}$ \\
\hline $\begin{array}{l}\text { Absence of an OCS-use } \\
\text { monitoring system }\end{array}$ & $\begin{array}{l}\text { OCS overuse } \\
\text { Adverse effects related to OCS } \\
\text { use } \\
\text { Delay in using alternative } \\
\text { therapies }\end{array}$ \\
\hline
\end{tabular}

Abbreviation: OCS, oral corticosteroids. 
Table 4 Suggestions for Overcoming the Barriers to Effective Management of Severe Asthma

\begin{tabular}{|c|c|}
\hline Target Audience & Suggestions \\
\hline $\begin{array}{l}\text { Pulmonary/allergy centers with the } \\
\text { authority to prescribe biologic } \\
\text { drugs }\end{array}$ & $\begin{array}{l}\text { Creating dedicated agendas and } \\
\text { preferential channels for patients } \\
\text { with severe asthma } \\
\text { Establishing a diagnostic- } \\
\text { therapeutic pathway for severe } \\
\text { asthma } \\
\text { Conducting interdisciplinary } \\
\text { internal meetings (otolaryngologist, } \\
\text { psychologists, gastroenterologists, } \\
\text { interventionists) } \\
\text { Keeping clinical registries to support } \\
\text { the network among centers }\end{array}$ \\
\hline $\begin{array}{l}\text { Pulmonologists/allergists without } \\
\text { the authority to prescribe biologic } \\
\text { drugs }\end{array}$ & $\begin{array}{l}\text { Establishing collaboration between } \\
\text { GPs/specialists who can prescribe } \\
\text { biologic agents and specialists who } \\
\text { cannot prescribe biologic agents } \\
\text { Conducting regular training on } \\
\text { referral criteria } \\
\text { Conducting training to become } \\
\text { a prescribing center } \\
\text { Collaborating with specialists who } \\
\text { treat comorbidities }\end{array}$ \\
\hline Patients and caregivers & $\begin{array}{l}\text { Improving public awareness of } \\
\text { severe asthma } \\
\text { Education about severe asthma in } \\
\text { schools } \\
\text { Supporting patients' associations } \\
\text { Providing support for scientific } \\
\text { societies }\end{array}$ \\
\hline GPs & $\begin{array}{l}\text { Conducting refresher courses on } \\
\text { severe asthma } \\
\text { Creating a network with specialist } \\
\text { centers } \\
\text { Providing GPs with objective } \\
\text { parameters for recognizing severe } \\
\text { asthma (flow charts, alerts for } \\
\text { indicators of uncontrolled asthma) } \\
\text { Training in spirometry and } \\
\text { diagnostic techniques }\end{array}$ \\
\hline Emergency units & $\begin{array}{l}\text { Improving identification of patients } \\
\text { with severe asthma and facilitating } \\
\text { their referral to appropriate } \\
\text { specialists } \\
\text { Improving training on how to } \\
\text { recognize severe asthma } \\
\text { Promoting collaboration within } \\
\text { hospitals } \\
\text { Promoting collaboration between } \\
\text { first aid providers and biologic } \\
\text { prescribing centers }\end{array}$ \\
\hline
\end{tabular}

(Continued)
Table 4 (Continued).

\begin{tabular}{|l|l|}
\hline Target Audience & Suggestions \\
\hline Hospital pharmacists & $\begin{array}{l}\text { Increasing the involvement of } \\
\text { hospital pharmacists in the } \\
\text { management of severe asthma } \\
\text { Taking advantage of big data } \\
\text { available to pharmacists (eg about } \\
\text { over-prescription of OCS) } \\
\text { Conducting video tutorials in } \\
\text { pharmacies }\end{array}$ \\
\hline $\begin{array}{l}\text { Providing spirometry assessments } \\
\text { in hospital pharmacies }\end{array}$ \\
\hline Payers & $\begin{array}{l}\text { Establishing outpatient clinics } \\
\text { dedicated to asthma } \\
\text { Implementing Integrated Care } \\
\text { Pathways } \\
\text { Collection of Italian } \\
\text { epidemiological data and } \\
\text { conducting pharmacoeconomic } \\
\text { analyses on the use of biologics } \\
\text { Establishing regional networks }\end{array}$ \\
\hline All target audiences & $\begin{array}{l}\text { Creating a hub-and-spoke } \\
\text { Icollaborative network } \\
\text { Providing preferential channels for } \\
\text { specialist visits for patients with } \\
\text { severe asthma } \\
\text { Creating a network connecting all } \\
\text { stakeholders at the regional level } \\
\text { Imitating existing local best } \\
\text { practices }\end{array}$ \\
\hline
\end{tabular}

Abbreviations: GP, general practitioner; OCS, oral corticosteroids.

\section{Possible Solutions}

The measures suggested by participants for addressing the various barriers are listed in Table 4. All participants agreed on the need to create a multidisciplinary group of specialists in order to improve the management of patients with severe asthma and to implement patient education. This should be achieved by educational initiatives for multidisciplinary teams, meetings with local experts, instruments for the creation of a flow chart for referral or connection with local experts, and sessions to improve knowledge in specialized centers. Several clinical instruments are believed to be useful for specialists in improving the management of severe asthma: referral networks, integrated care pathways, phenotyping and treatment algorithms, tracking of exacerbations, and examination of electronic medical records for patients with uncontrolled asthma. Multidisciplinary networks and specific routes of 
referral should be organized and implemented in clinical practice in each area of Italy.

\section{Expert Opinion on Addressing Barriers to Effective Management of Severe Asthma in the Context of the Italian Health Service}

We suggest several solutions to improve disease control, reduce the risks associated with poor asthma control, optimize healthcare resource utilization, and implement the Charter in the context of the Italian Health Service. These potential solutions take into consideration the results of discussions held during the macroregional events.

- Considering that the use of OCS is often associated with adverse events, therapeutic strategies that reduce the need for OCS, while also achieving asthma control, should be adopted. ${ }^{7,35}$ The biologic therapies targeting the IL-5/IL-5R $\alpha$ and IL-4 pathways have been shown to reduce the maintenance dose of OCS in patients with severe asthma. ${ }^{36-39}$

- Better adherence to treatment guidelines, particularly with respect to ICS, should be encouraged. ${ }^{16,40,41}$

- Medical education should focus on the correct application of asthma treatment guidelines in order to overcome unnecessary prescriptions. Patients should be informed about the correct inhaler technique and provided with medical information to enable them to understand the nature of their condition and treatments. ${ }^{1}$ An improvement in communication and care coordination between GPs and specialists may help to increase diagnostic and treatment capacities in primary care, improve referral, promote better use of specialist asthma centers, and ensure the more timely and appropriate prescription of biologic therapy. Many patients with asthma overestimate the extent of their asthma control. ${ }^{42}$ Therefore, central to the primary care management of asthma is a thorough understanding by GPs of what constitutes asthma control, so that all patients who are not achieving control can be promptly identified and the reasons for poor control identified. Patient adherence should be thoroughly investigated, and patients should be evaluated for attitudes and beliefs that may be negatively impacting adherence, as well as other factors, such as depression, anxiety, or substance abuse. ${ }^{28,33}$

- Regional health systems should introduce better diagnostic and therapeutic pathways, and GPs and specialists should be provided with diagnostic algorithms designed specifically for severe asthma. There should be dedicated treatment pathways for patients with severe asthma, ideally involving referral to a specialist center, where these patients can be managed by a multidisciplinary team experienced in complex asthma management. Such centers are best placed to ensure that patients undergo phenotypic assessment and receive prompt treatment with the most appropriate agent for their asthma.

- Healthcare is publicly funded in Italy and organized regionally, which can lead to differences in healthcare access between regions. The Charter described above recommends consistent and universal access to healthcare for all patients with severe asthma, which requires a coordinated approach overseen at the national level. Therefore, a Population Health Management approach should be introduced to improve clinical and financial outcomes in severe asthma. Individual patients should be monitored and data should be aggregated. Relevant clinical data should be shared by GPs, specialists and hospitals. The use of population-level data with treatment outcomes is expected to produce actionable analytics for providers that would help improve efficiency and patient care at a regional and local level. Effective division of labor, between specialists who are responsible for planning therapeutic interventions and GPs who are in charge of follow-up, should be promoted. Specialists should not be concentrated in single centers, but should move according to patients' needs.

- Minimal requirements for asthma centers should be formulated.

- Payers should be involved in improving healthcare system organization and reducing waiting times for specialist consultation.

- Pharmacoeconomic analyses should be performed to support all initiatives in this field to identify the most cost-effective approaches to comprehensive patient care.

\section{Managing Severe Asthma Patients During the COVID- I 9 Pandemic}

Beginning in early 2020, the world has been facing a new pandemic caused by the SARS-CoV-2 virus (COVID-19), which causes severe acute respiratory syndrome. Patients with asthma are at risk of experiencing exacerbations triggered by COVID-19 infection. ${ }^{43}$ GINA, ${ }^{44}$ the UK 
National Institute for Health and Care Excellence (NICE) ${ }^{45}$ and the Italian Associazione Allergologi Immunologi Italiani Territoriali e Ospedalieri (AAITO) ${ }^{46}$ and Societa' Italiana di Allergologia, Asma ed Immunologia Clinica (SIAAIC) ${ }^{47}$ guidelines recommend that i) patients should avoid accessing hospitals to reduce their risk of becoming infected; ii) patients should continue to receive ICS, OCS, or biologic therapies as prescribed and treatment interruptions should be avoided; and iii) if possible, patients should self-administer treatments at home after receiving appropriate training and written instructions. ${ }^{44,45}$ Thus, patients with severe asthma who are receiving biologic treatments should continue the treatment by self-administration, whenever possible. ${ }^{44-47}$

The COVID-19 pandemic will have a profound impact on modern medicine and is already reshaping the patientphysician relationship. A number of measures can be implemented to protect patients with asthma, as described in an article detailing the experience of physicians at the Allergy Clinic of the Humanitas Research Hospital in Milan, Italy. ${ }^{48}$ COVID-19-free zones were established to reduce within-hospital transmission. Before entering these zones, patients were screened for signs of active infection, underwent hand sanitization procedures, and were provided with surgical masks. Patients with severe or uncontrolled asthma were instructed to arrive for their scheduled appointments at predetermined times and to maintain social distancing. On the other hand, patients with mildto-moderate symptoms or well-controlled disease were transitioned to a telemedicine service that included phone, video, and email consultations. Patients were asked to self-administer biologic drugs that were delivered to their homes. ${ }^{48}$ Hospitals treating patients with asthma should implement these or similar measures, depending on local circumstances, in order to maintain disease control in patients with asthma and reduce the risk of exacerbations that may necessitate hospitalization. ${ }^{43}$

\section{Conclusions}

In Italy, as in other European countries, severe asthma places a significant burden on patients, healthcare systems, and society. Therefore, it is important to ensure effective management of this condition, which is hindered by several unmet needs. These include poor disease control and adherence to clinical practice guidelines, treatment-related adverse events, and adverse health outcomes, which may include asthma-related death in some cases. In order to address these unmet needs in Italy and to meet the Charter for patient care, it is necessary to implement a series of actions: i) decrease the burden of inappropriate OCS usage by maximizing the use of advanced therapies, such as biologic drugs; ii) increase education efforts targeted at physicians and patients; iii) improve multidisciplinary communication and care coordination, to accelerate referral and severe asthma diagnosis and pheno-endotyping; iv) introduce diagnostic and therapeutic protocols for severe asthma at the regional or local level; and v) establish costeffective structural changes to healthcare services, reducing waiting times for specialist consultation and facilitating access to targeted biologic therapies.

\section{Abbreviations}

AAITO, Associazione Allergologi Immunologi Italiani Territoriali e Ospedalieri; ATS, American Thoracic Society; COVID-19, SARS-CoV-2 virus; ERS, European Respiratory Society; GINA, Global Initiative for Asthma; GP, general practitioner; ICS, inhaled corticosteroids; IL, interleukin; OCS, oral corticosteroids; NHS, National Health Service; NICE, National Institute for Health and Care Excellence; SANI, Severe Asthma Network in Italy; SIAAIC, Società Italiana di Allergologia, Asma ed Immunologia Clinica; TENOR, The Epidemiology and Natural History of Asthma, Outcomes and Treatment Regimens; UK, United Kingdom.

\section{Data Sharing Statement}

Survey data are available from the corresponding author [PP] on request.

\section{Acknowledgments}

The authors thank Laura Brogelli, who drafted the outline on behalf of Springer Healthcare Communications and Georgii Filatov of Springer Healthcare Communications who developed the first draft. This editorial support was funded by AstraZeneca.

\section{Author Contributions}

All authors have participated in the PRECISION project, an AstraZeneca organized and funded program to promote the management of severe asthma around the world. All authors were members of the expert panel that reviewed the literature and the outcomes of the macroregional events, and developed the summary of recommendations. Dr. Paggiaro reviewed the manuscript and prepared the final version of the article. All Authors contributed in the conception of the reported work and in the literature analysis, critically revised 
and approved all the drafts, agreed on the target journal, approved the final version and agreed to take responsibility and be accountable for the contents of the article.

\section{Funding}

The macroregional events were funded by AstraZeneca. The expert panel meeting was funded by AstraZeneca as part of the manuscript development.

\section{Disclosure}

Dr. Paggiaro has received institutional and personal grants for research and education from ALK-Abellò, AstraZeneca, Chiesi, Glaxo Smith Kline, Guidotti, Menarini, Mundipharma, Novartis, and Sanofi. Dr. Trama reports grants from Fisioair Srl, grants from K. Link srl, grants from Mediacom Srl, grants from Boehringer Ingelheim, grants from Beneventi srl, outside the submitted work. Dr. Croce has received personal grants for research and education from AbbVie, Allergan, Astellas, Bayer, Becton Dickinson, Dompè, General Electric Healthcare, Gilead Science, Glaxo Smith Kline, Italfarmaco, MSD, Pfizer, Sanofi, Shire, Takeda, and ViiV Healthcare. Dr. Canonica has received research grants, been a speaker, or received advisory board fees from Menarini, Alk-Abellò, Allergy Therapeutics, AstraZeneca, Boehringer Ingelheim, Chiesi Farmaceutici, Genentech, Guidotti-Malesci, Glaxo Smith Kline, Hal Allergy, Mylan, Merck, Merck Sharp \& Dome, Mundipharma, Novartis, Regeneron, Roche, Sanofi-Aventis, Sanofi-Genzyme, Stallergenes-Greer, UCB Pharma, Uriach Pharma, Valeas, and Vibor-Pharma. Dr. Barbaglia has no conflicts of interest to declare. Dr. Centanni has received institutional grants for research and education from AstraZeneca, Chiesi, Valeas and Boehringer Ingelheim and personal fees from Glaxo Smith Kline, Novartis, Chiesi, Menarini, AstraZeneca, Valeas, Boehringer Ingelheim, Guidotti Malesci. Dr. Desideri has no conflicts of interest to declare. Dr. Giustini has no conflicts of interest to declare. Dr. Micheletto has been a speaker, or received advisory board fees from AstraZeneca, Glaxo Smith Kline, Sanofi, Novartis, Menarini, Guidotti, Chiesi, Zambon, Berlin Chemie. Dr. Musarra has received advisory board fees from Glaxo Smith Kline, AstraZeneca, Sanofi Genzyme and Mylan. Dr. Scichilone has no conflicts of interest to declare. Dr. Zedda has received institutional and personal grants for research and education from AstraZeneca, Guidotti, Menarini. The authors report no other conflicts of interest in this work.

\section{References}

1. Global Initiative for Asthma. 2020 GINA report, global strategy for asthma management and prevention; 2020. Available from: https:// ginasthma.org/wp-content/uploads/2020/04/GINA-2020-full-report_final__wms.pdf. Accessed October 13, 2020.

2. Global Asthma Network. The global asthma report2020; 2020. Available from: www.ginasthma.org. Accessed October 13, 2020.

3. Chung KF, Wenzel SE, Brozek JL, et al. International ERS/ATS guidelines on definition, evaluation and treatment of severe asthma. Eur Respir J. 2014;43(2):343-373. doi:10.1183/09031936.00202013

4. Hekking PP, Wener RR, Amelink M, et al. The prevalence of severe refractory asthma. J Allergy Clin Immunol. 2015;135(4):896-902. doi:10.1016/j.jaci.2014.08.042

5. Larsson K, Stallberg B, Lisspers K, et al. Prevalence and management of severe asthma in primary care: an observational cohort study in Sweden (PACEHR). Respir Res. 2018;19(1):12. doi:10.1186 s12931-018-0719-x

6. Taylor DR, Bateman ED, Boulet LP, et al. A new perspective on concepts of asthma severity and control. Eur Respir J. 2008;32 (3):545-554. doi:10.1183/09031936.00155307

7. Song WJ, Lee JH, Kang Y, et al. Future risks in patients with severe asthma. Allergy Asthma Immunol Res. 2019;11(6):763-778. doi:10.4168/aair.2019.11.6.763

8. Zeiger RS, Schatz M, Li Q, et al. Burden of chronic oral corticosteroid use by adults with persistent asthma. J Allergy Clin Immunol Pract. 2017;5(4):1050-1060, e1059. doi:10.1016/j.jaip.2016.12.023

9. Lefebvre P, Duh MS, Lafeuille MH, et al. Burden of systemic glucocorticoid-related complications in severe asthma. Curr Med Res Opin. 2017;33(1):57-65. doi:10.1080/03007995.2016.1233101

10. Foster JM, McDonald VM, Guo M, et al. "I have lost in every facet of my life": the hidden burden of severe asthma. Eur Respir J. 2017;50(3):1700765. doi:10.1183/13993003.00765-2017

11. Eassey D, Reddel HK, Foster JM, et al. I've said I wish I was dead, you'd be better off without me": a systematic review of people's experiences of living with severe asthma. J Asthma. 2019;56 (3):311-322. doi:10.1080/02770903.2018.1452034

12. Antonicelli L, Bucca C, Neri M, et al. Asthma severity and medical resource utilisation. Eur Respir J. 2004;23(5):723-729. doi:10.1183/ 09031936.04.00004904

13. Canonica GW, Colombo GL, Bruno GM, et al. Shadow cost of oral corticosteroids-related adverse events: a pharmacoeconomic evaluation applied to real-life data from the Severe Asthma Network in Italy (SANI) registry. World Allergy Organ J. 2019;12(1):100007. doi:10.1016/j.waojou.2018.12.001

14. Chung LP, Upham JW, Bardin PG, et al. Rational oral corticosteroid use in adult severe asthma: a narrative review. Respirology. 2020;25 (2):161-172. doi:10.1111/resp.13730

15. Global Initiative for Asthma. 2014 GINA report, global strategy for asthma management and prevention; 2014. Available from: https:// ginasthma.org/wp-content/uploads/2019/01/2014-GINA.pdf. Accessed October 13, 2020.

16. Global Initiative for Asthma. 2019 GINA report, global strategy for asthma management and prevention; 2019. Available from: https:// ginasthma.org/wp-content/uploads/2019/06/GINA-2019-main-reportJune-2019-wms.pdf. Accessed October 13, 2020.

17. Price DB, Trudo F, Voorham J, et al. Adverse outcomes from initiation of systemic corticosteroids for asthma: long-term observational study. J Asthma Allergy. 2018;11:193-204. doi:10.2147/JAA.S176026

18. Volmer T, Effenberger $\mathrm{T}$, Trautner $\mathrm{C}$, et al. Consequences of long-term oral corticosteroid therapy and its side-effects in severe asthma in adults: a focused review of the impact data in the literature. Eur Respir J. 2018;52(4):1800703. doi:10.1183/13993003.007032018 
19. Bleecker ER, Menzies-Gow AN, Price DB, et al. Systematic literature review of systemic corticosteroid use for asthma management. Am J Respir Crit Care Med. 2019;201(3):276-293. doi:10.1164/ rccm.201904-0903SO

20. Heffler E, Blasi F, Latorre M, et al. The Severe Asthma Network in Italy: findings and perspectives. J Allergy Clin Immunol Pract. 2019;7(5):1462-1468. doi:10.1016/j.jaip.2018.10.016

21. Vetrano DL, Zucchelli A, Bianchini E, et al. Patterns of oral corticosteroids use in primary care patients with severe asthma. Respir Med. 2020;166:105946. doi:10.1016/j.rmed.2020.105946

22. D'Amato G, Vitale C, Molino A, et al. Asthma-related deaths. Multidiscip Respir Med. 2016;11:37. doi:10.1186/s40248-0160073-0

23. Price D, Bjermer L, Bergin DA, et al. Asthma referrals: a key component of asthma management that needs to be addressed. J Asthma Allergy. 2017;10:209-223. doi:10.2147/ JAA.S 134300

24. Levy ML, Andrews R, Buckingham R, et al. Why asthma still kills. The National Review of Asthma Deaths (NRAD); 2014. Available from: https://www.rcplondon.ac.uk/file/868/download. Accessed October 13, 2020.

25. Bourdin A, Molinari N, Vachier I, et al. Mortality: a neglected outcome in OCS-treated severe asthma. Eur Respir J. 2017;50 (5):1701486. doi:10.1183/13993003.01486-2017

26. Ekström M, Nwaru BI, Hasvold P, et al. Oral corticosteroid use, morbidity and mortality in asthma: a nationwide prospective cohort study in Sweden. Allergy. 2019;74(11):2181-2190. doi:10.1111/all.13874

27. Menzies-Gow A, Canonica GW, Winders TA, et al. A charter to improve patient care in severe asthma. Adv Ther. 2018;35 (10):1485-1496. doi:10.1007/s12325-018-0777-y

28. Baiardini I, Sicuro F, Balbi F, et al. Psychological aspects in asthma: do psychological factors affect asthma management? Asthma Res Pract. 2015;1:7. doi:10.1186/s40733-015-0007-1

29. Byrnes PD. Why haven't I changed that? Therapeutic inertia in general practice. Aust Fam Physician. 2011;40(1-2):24-28.

30. Chiu KC, Boonsawat W, Cho SH, et al. Patients' beliefs and behaviors related to treatment adherence in patients with asthma requiring maintenance treatment in Asia. J Asthma. 2014;51(6):652-659. doi:10.3109/02770903.2014.898772

31. Harris DA, Mainardi A, Iyamu O, et al. Improving the asthma disparity gap with legal advocacy? A qualitative study of patient-identified challenges to improve social and environmental factors that contribute to poorly controlled asthma. J Asthma. 2018;55(8):924-932. doi:10.1080/02770903.2017.1373393

32. Lingner H, Burger B, Kardos $P$, et al. What patients really think about asthma guidelines: barriers to guideline implementation from the patients' perspective. BMC Pulm Med. 2017;17(1):13. doi:10.1186/ s12890-016-0346-6

33. Majellano EC, Clark VL, Winter NA, et al. Approaches to the assessment of severe asthma: barriers and strategies. J Asthma Allergy. 2019;12:235-251. doi:10.2147/JAA.S178927

34. Larenas-Linnemann D, Fernandez-Vega M, Rodriguez-Gonzalez M, et al. An online survey detected knowledge gaps and cost-saving opportunities in asthma maintenance treatment among allergists, pulmonologists, ENTs and primary care. World Allergy Organ J. 2019;12(12):100084. doi:10.1016/j.waojou.2019.100084
35. Pavord ID. Oral corticosteroid-dependent asthma: current knowledge and future needs. Curr Opin Pulm Med. 2019;25(1):51-58. doi:10.1097/MCP.0000000000000541

36. Bel EH, Wenzel SE, Thompson PJ, et al. Oral glucocorticoid-sparing effect of mepolizumab in eosinophilic asthma. $N$ Engl J Med. 2014;371(13):1189-1197. doi:10.1056/NEJMoa1403291

37. Nair P, Wenzel S, Rabe KF, et al. Oral glucocorticoid-sparing effect of benralizumab in severe asthma. $N$ Engl $J$ Med. 2017;376 (25):2448-2458. doi:10.1056/NEJMoa1703501

38. Rabe KF, Nair P, Brusselle G, et al. Efficacy and safety of dupilumab in glucocorticoid-dependent severe asthma. N Engl J Med. 2018;378 (26):2475-2485. doi:10.1056/NEJMoa1804093

39. Bourdin A, Shaw D, Menzies-Gow A, et al. Two-year integrated steroid-sparing analysis and safety of benralizumab for severe asthma. J Asthma. 2019;1-9.

40. Heffler E, Bagnasco D, Canonica GW. Strategies to reduce corticosteroid-related adverse events in asthma. Curr Opin Allergy Clin Immunol. 2019;19(1):61-67. doi:10.1097/ACI.0000000000000493

41. Papi A, Blasi F, Canonica GW, et al. Treatment strategies for asthma: reshaping the concept of asthma management. Allergy Asthma Clin Immunol. 2020;16:75. doi:10.1186/s13223-020-00472-8

42. Kritikos V, Price D, Papi A, et al. A multinational observational study identifying primary care patients at risk of overestimation of asthma control. NPJ Prim Care Respir Med. 2019;29(1):43. doi:10.1038/ s41533-019-0156-4

43. Shaker MS, Oppenheimer J, Grayson M, et al. COVID-19: pandemic contingency planning for the allergy and immunology clinic. $J$ Allergy Clin Immunol Pract. 2020;8(5):1477-1488, e1475. doi:10.1016/j.jaip.2020.03.012

44. Global Initiative for Asthma. COVID-19: GINA answers to frequently asked questions on asthma management; 2020. Available from: https://ginasthma.org/wp-content/uploads/2020/03/FinalCOVID-19-answers-to-frequent-questions-25.3.2020-1.pdf.

Accessed October 13, 2020.

45. National Institute for Health and Care Excellence. COVID-19 rapid guideline: severe asthma; 2020. Available from: https:/www.nice. org.uk/guidance/ng166/resources/covid19-rapid-guideline-severeasthma-pdf-66141904108741. Accessed October 13, 2020.

46. Associazione Allergologi Immunologi Italiani Territoriali e Ospedalieri. Useful information for allergic patients in times of coronavirus [in Italian]; 2020. Available from: https://docs.biomedia.net/2020/aaiito/ Comunicato\%20Covid19.pdf. Accessed October 13, 2020.

47. Societa' Italiana di Allergologia AeIC. SIAAIC address document for respiratory allergic patients and the Centers for Allergy, Asthma and Immunology Clinic; 2020. Available from: http://www.siaaic.org/wpcontent/uploads/2020/05/Documento-di-Indirizzo-SIAAIC-v2.pdf. Accessed October 13, 2020.

48. Malipiero G, Paoletti G, Puggioni F, et al. An academic allergy unit during COVID-19 pandemic in Italy. J Allergy Clin Immunol. 2020;146(1):227. doi:10.1016/j.jaci.2020.04.003 


\section{Publish your work in this journal}

The Journal of Asthma and Allergy is an international, peer-reviewed open-access journal publishing original research, reports, editorials and commentaries on the following topics: Asthma; Pulmonary physiology; Asthma related clinical health; Clinical immunology and the immunological basis of disease; Pharmacological interventions and new therapies. The manuscript management system is completely online and includes a very quick and fair peer-review system, which is all easy to use. Visit http://www.dovepress.com/testimonials.php to read real quotes from published authors.

Submit your manuscript here: https://www.dovepress.com/journal-of-asthma-and-allergy-journal 